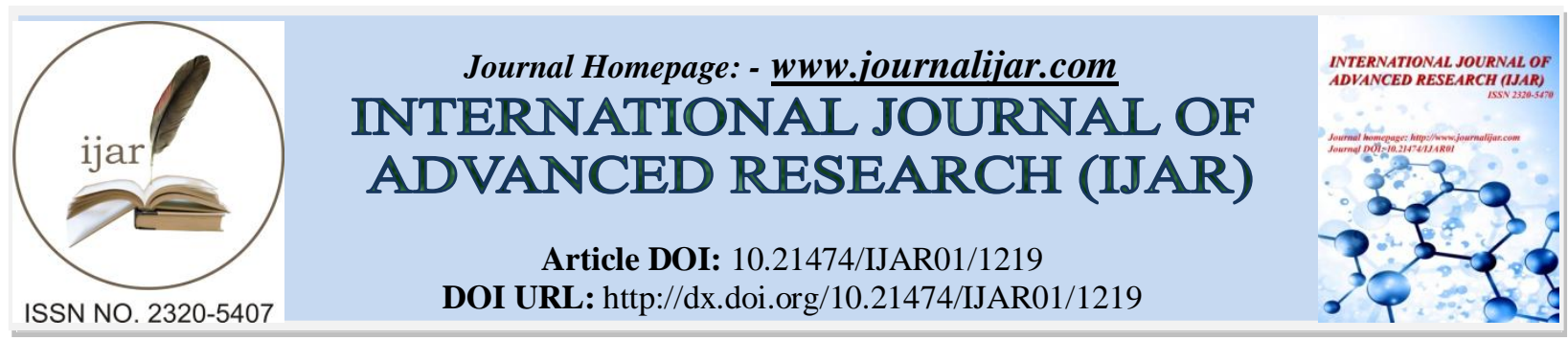

RESEARCH ARTICLE

\title{
MICROBIAL INTERACTIONS IN TEXTILE INDUSTRY: A REVIEW
}

Farida P. Minocheherhomji.

Department of Microbiology, B. P. Baria Science Institute, NAVSARI - 396445, Gujarat, India.

\section{Manuscript Info}

Manuscript History

Received: 15 June 2016

Final Accepted: 22 July 2016

Published: August 2016

Key words:-

Microbial enzymes in textiles,

Cotton fiber, Desizing,

Biodeterioration.

\section{Abstract}

The main aim of this review article is to focus on the beneficial as well as the harmful impact of microorganisms on textile fibers. Nature and natural sources are a scarce commodity compared to the increasing global population. Research has been diverted to the use of microorganisms in the evolution of newer processes and bettering the existing ones in textile industry which serves to satisfy one of the essential needs of man; being the basic requirement of covering their bodies, which is as ancient as the nomadic human being itself predating to the historic age. Similar interactions of microorganisms in cotton production are also well known. So this review article is a step to understand our natural resources and conserve them for satisfying the bare necessity of human life.

\section{Introduction:-}

The basic need for covering the body led to the exploration of different natural fiber sources like Cotton, Jute, Wool, Natural silk. Many important factors played crucial roles in the development and refinement of these fibers. Important primary factor in this aspect is the abundant availability of the fiber followed by manufacturing processes which involves lesser inputs to get a versatile fabric at an affordable cost. Out of all the natural fibers, cotton has proved itself to be the historical fiber for man, stretching as far as history can take us. Due to the all round versatility of this fiber, it has found numerous uses in the life cycle of man. The numerous advantages of this fiber have made it to be the first preference for apparels, thus leading to its development and production since ages at an unorganized small scale. This gained momentum some 200 years back with the advent of industrialization and many major changes including modifications in its processes and applicability has been carried out in the last few decades.

Recent trends in the cultivation of cotton is towards the incorporation of innovative farming techniques coupled with natural fertilizers, compost without any synthetic chemical fertilizers, insecticides and pesticides. Available data suggests that less than $3 \%$ of the land in the world is used for the plantation of cotton.

\section{Microorganisms Causing Bio-deterioration and as Bio-Cleaners:-}

The outcome of the activity of microorganisms on any material leading to undesirable change in its properties is generally referred to as Bio-deterioration. But, all such breakdowns of materials by microorganisms are not undesirable, but it is beneficial to the environment as it is a natural way of cleaning the refuse. Such degradation is an essential process in the maintenance of the surrounding environment. It is also a means of recycling many

Corresponding Author:- Dr. (Mrs.) Farida P. Minocheherhomji.

Address:- Department of Microbiology, B. P. Baria Science Institute, NAVSARI 396445, Gujarat, India. 
essential elements contained in these materials. However, when it is an unwanted process such as when textiles are affected by the microorganisms, then it can be a serious problem to manufacturers and users alike ${ }^{2,4,6}$.

The detrimental role played by microbes in textiles is the mildew or rotting damage onto the fabrics itself, and also the indirect loss to the textile industry encountered in the hydrolysis of natural Guar and Tamarind Kernel Powder thickeners / gums employed in the printing process, which is a main part of the textile processing works.

Textile fabrics are of two types. Fabrics that are either purely manufactured from natural fiber sources like Cotton, Jute, Wool, Natural silk, or artificial or man-made fibers like Viscose or Regenerated cellulose, Polyester, Nylon, Man-made silk, rayon. Blends of both these natural and artificial sources are also manufactured on a large scale.

On the contrary, this microbial growth can very well be incorporated in a beneficial manner in certain processing steps for efficient processing of these natural fibers based fabrics. Microbes are extensively used in processes like Enzymatic desizing, a vital step in the processing of natural fiber fabrics ${ }^{\mathbf{1}, \mathbf{6}, \mathbf{6}}$. Also, microbes have been found to play a vital role in increasing the agricultural production of cotton in farming stage or the cotton cropping system. Microbes are also employed in the effluent treatment of different industries, which is an eco-friendly method of sewage disposal with almost nil impact on the environment.

\section{Role of Microbial Enzymes in Cotton Processing:-}

The use of enzymes in the textile industry is an example of white industrial biotechnology, which allows the development of environmentally friendly technologies in fiber processing and strategies to improve the final product quality. The consumption of energy and raw-materials, has led to an increased awareness of environmental concerns related to the use and disposal of chemicals into landfills, water or release into the air during chemical processing of textiles, as well as conservation of the depleting non-renewable sources of energy. These are the principal reasons for the application of enzymes in finishing of textile materials ${ }^{1,5,6,8}$.

Processing of natural fiber fabrics, in which cotton acquires the main and primary fiber to have universal acceptance, is a long and time consuming process involving many technological aspects to be taken care of. The main processing steps with the ancillary processes are Bleaching which includes Shearing and Cropping, Singeing, Desizing, followed by Caustic $(\mathrm{NaOH})$ boil, Mercerizing: Chemik-Peroxide boil, Dyeing, Printing, Finishing and Checking/Folding and Packing prior to dispatch of the quality fabric to the market.

Out of all the above steps in cotton processing, desizing is the main step in which microbial action helps in better and quick removal of the starch based sizing material applied onto the yarn before weaving to impart it strength and avoid mechanical breakages during weaving. Desizing with very less impact on the environment without the use of corrosive acids and alkalies is utmost necessary for the subsequent successful dyeing and printing operations involved in textile processing.

\section{Role of Microbial Enzymes in Textile Processing:-}

The word 'Enzymes' is coined from the Greek word 'Enzymos' meaning 'in the cell' or 'from the cell'. They are the protein substances made up of more than 250 amino acids, grouped based on specificity. The concept of treating fabrics with enzymes to improve their surface properties was first developed in Japan in 1989. The concept has assumed significant importance due to the current environmental concerns for the maintenance of clean and ecofriendly conditions necessary for the ultimate survival of all forms of life. Enzymes are grouped in the following groups according to their modes of action:

1. Oxidoreductases: Action by oxidation and reduction reactions.

2. Transference: Transfer of functional group.

3. Hydrolases: Action by hydrolysis reaction.

4. Lyases: Addition of double bond or its reverse.

5. Isomerses: Isomerisation.

6. Ligases: Formation of bonds with ATP cleavages.

Enzymes react with their substrates at a region within the protein molecule which is called active site. The active site of the enzyme must have the necessary structure characteristics to recognize the right substrate and the proper chemical environment to make the reaction happen. Commercial sources of enzymes are obtained from any biological source like animal, plants and microbes. These naturally occurring enzymes are generally not readily 
available in sufficient quantities required for industrial use, but the number of proteins being produced using recombinant techniques known as 'Protein Engineering' is exponentially increasing. By this method of 'Protein Engineering', under favorable conditions, living cells can be encouraged to produce more enzymes then they could normally make, as well as, they could make a slightly modified type of enzyme with improved properties like higher specificity, stereo specificity, stability and performance in industrial reaction processes. Screening approaches are being performed to rapidly identify enzymes with potential industrial application. These enzymes usually operate under milder conditions of temperature and $\mathrm{pH}^{1,5.6,8}$.

Textile processing has reaped great benefits in terms of both environmental impact and product quality through the use of enzymes. From the 7000 enzymes known, only about 75 have found to be useful in textile processing. Enzymes are biodegradable products capable of efficient working under milder conditions, thus conserving precious nonrenewable sources of energy. Enzymes are biocatalysts working to specific perfection in very small amounts. This also results in savings of packing costs and handling and transportation charges. The principal enzymes used in textile industry are hydrolases and oxidoreductases. The group of hydrolases includes amylases, cellulases, proteases, pectinases and lipases or esterases.

Amylases were the only enzymes applied in textile processing until the 1980s. These enzymes are still used to remove starch-based sizes from fabrics after weaving.

Cellulases have been employed to enzymatically remove fibrils and fuzz fibers, and have also successfully been introduced to the cotton textile industry. Further applications have been found for these enzymes to produce the worn-out look of denim apparel and other garments. Proteolytic enzymes have the potential to remove wool fiber scales, resulting in improved anti-felting property.

Esterases have been successfully studied for the partial hydrolysis of synthetic fiber surfaces, improving their hydrophilicity and aiding further finishing steps.

Besides hydrolytic enzymes, oxidoreductases have also been used as powerful tools in various textile-processing steps. Catalases have been used to remove $\mathrm{H}_{2} \mathrm{O}_{2}$ after bleaching, thus reducing water consumption. An outstanding example of the high catalytic power of the enzymes is the activity of catalase enzyme. One molecule of enzyme catalase is able to convert $5 \times 10^{6}$ molecules of hydrogen peroxide into hydrogen and water in 60 seconds.

In the textile industry, one of the first area in which use of enzymes has been explored is in the field of desizing of textiles. A size is a starch based product that is coated on to the cotton fibers to lubricate and strengthen them to withstand the abrasive mechanical stress and prevent its breakage during the weaving process. Although many different compounds have been used to size fabrics, starch and its derivatives are the most common because of their excellent film forming capacity, availability and relatively low cost.

Enzymes developed in the last 20 years have replaced acids, alkalies and starch solubilising mineral chemicals used by the textile processing units. Today, enzymes are used to treat and modify fibers, particularly during textile processing and in after-care of textiles later. They are used to enhance the preparation of cotton yarn prior to weaving, reduce the add-on impurities during weaving, minimize "pulls" in fabric, or as pre-treatment before dyeing to reduce the rinsing time and improve color penetration and brilliance. This has led to water and energy conservation in processing, which extends to $30 \%$ water savings and $60 \%$ energy savings compared to standard processing, which is a major need of the day.

New enzymatic processing sequences have been implemented in Scouring, Bleaching, Bio-finishing, as well as in Degumming of Silk and Anti-felting and Carbonization of Wool, in which the treatment with proteases modifies the surface of wool and silk fibers to achieve a unique finish.

\section{Microorganisms Responsible for Degradation of textiles:-}

Biodegradation or biodeterioration has been defined as an undesirable change in the properties of a material caused by the vital activities of organisms. Plant fibers such as cotton, flax (linen), jute and hemp are very susceptible to attack by cellulolytic or cellulose digesting fungi and bacteria. Textiles made from natural fibers are generally more susceptible to biodeterioration than are the synthetic man-made fibers. Microorganisms may attack the entire substrate, textile fibers as a whole, or the attack may only be on a single component of the substrate, such as 
plasticizers contained therein, or grow on dirt that has accumulated on the surface of a product. Even a mild surface growth can make a fabric look unattractive by the appearance of unwanted pigmentation. Heavy infestation, which results in rotting and breakdown of the fibers and subsequent physical changes such as a loss of strength or flexibility may cause the fabric to fail in service.

\section{Mildew or Rotting ${ }^{3,9}$ :-}

The main detrimental role played by these microbes in textiles is the mildew damage onto the fabric. Textiles manufactured from natural fibers are prone to fast deterioration then the synthetic fiber based textiles, due to their exposure to moist and humid environmental conditions coupled with heat and acidic or alkaline $\mathrm{pH}$. This is due to microbial growth in the textiles. Microbial activity can be prevented or minimized by keeping susceptible materials dry, as their growth starts on the surface if and when the relative humidity is high. Using antimicrobial agents and biocides during finishing also prevents microbial growth on garments. Hence, certain chemicals are applied for protection of textiles which are likely to be used in adverse conditions under which they remain wet or damp for long periods of time.

\section{Types of Antimicrobial Finish ${ }^{7}$ :-}

Antimicrobial finish is of two types based on their activity against microorganisms.

\section{Passive Antimicrobial Finish:-}

Passive materials do not contain any active antimicrobial substances but their surface or structure which is of antiadhesive type, is responsible for lowering the growth and presents a negative effect on the living conditions of microorganisms.

\section{Active Antimicrobial Finish:}

Materials containing active antimicrobial substances act upon either in the cell or on the cellular structure of the material.

\section{Conclusion:-}

This review article is compiled to bring out the awareness of the number and kinds of microorganisms associated with textile industry and the biochemical changes which such organisms can induce. A comprehensive review of textile microbiology has been presented in this article. The boons and banes of microorganisms in textiles have been briefly described for the betterment of the textile industry in particular and the human society at large in general.

\section{Bibliography:-}

1. Boryo DEA (2013); The effect of microbes on textile material: A review on the wayout so far; The international Journal of Engineering and Science (IJES); Vol. 2, Issue 8, 09-13.

2. Doshi R, Shelke V (2001); Enzymes in textile industry - An environment-friendly approach; Indian journal of Fiber and Textile Research; Vol.: 26, 202-205.

3. Hamlyn Paul F (1990, 1998); Talking rot... and mildew; Textiles, 1990, 19, 46-50 and also Published in the December 1998 issue of NWFG Newsletter (ISSN 1465-8054).

4. Hamlyn Paul F (1995); The impact of biotechnology on the textile industry; Textiles; 3, 6-10.

5. https://oecotextiles.wordpress.com/2011/12/02/enzymes-in textile-processing/ -- Enzymes in Textile Processing; O Eco Textiles - Indulgent Yet Responsible.

6. Minocheherhomji FP (2016); Microbes and Textiles - An Intrinsic Relationship; Research India Publications, located at Head Office: B-2/84, Ground Floor, Rohini Sector-16, Delhi-110089 INDIA.

7. Ramachandran T, Rajendrakumar K, Rajendran R (2004); Antimicrobial Textiles - an Overview; Biovation 1 6; IE (I) Journal, Vol. 84, 42-27.

8. Rita Araujo, Margarida Casal, Artur Cavaco-Paul (2008); Application of enzymes for textile fibers processing; Biocatalysis and Biotransformation, September; 26(5): 332349

9. UExcel Microbiology: Study Guide \& Test Prep / Science Courses; Microbes and the Clothing Industry; Chapter 19, Lesson 7. 